\title{
Role of house-dust mites in childhood asthma
}

\author{
J. K. SARSFIELD \\ From the University Departments of Immunology and Paediatrics and Child Health, General Infirmary, Leeds
}

\begin{abstract}
Sarsfield, J. K. (1974). Archives of Disease in Childhood, 49, 711. Role of house-dust mites in childhood asthma. The aetiological importance of the house-dust mite, Dermatophagoides sp., was examined in 133 asthmatic children referred to hospital. Evidence of sensitization to this allergen from positive skin tests and the presence of circulating specific IgE was found in the majority of these children and sensitization often began in the preschool years. In vitro studies of specific IgE levels were found to bear a close relation to nasal provocation tests and probably have an important place in the identification of offending allergens in the paediatric patient.

Ecological studies of the house-dust mite revealed its common occurrence in domestic environments, especially in the bed and bedroom. The mites were not found in hospital beds and only low levels of infestation were found in perambulators and cots and in residential schools for 'delicate' children. The findings stress the major importance of this allergen in the causation of childhood asthma.
\end{abstract}

The role of house-dust in the production of symptoms in asthma has been recognized for many years (Kern, 1921; Cooke, 1922). Dekker (1928) discussed the importance of house-mites in asthma and described how they could be successfully avoided. Dutch workers (Voorhorst, SpieksmaBoezeman, and Spieksma, 1964; Voorhorst et al., 1967) presented evidence that the mite Dermatophagoides pteronyssinus was the single most important allergenic component of European house-dust; and subsequent workers emphasized its widespread occurrence (Maunsell, Wraith, and Cunnington, 1968; Frankland, 1971) and its clinical significance in allergic asthma (Maunsell et al., 1968; McAllen, Assem, and Maunsell, 1970).

Few studies (Smith et al., 1969; Bullock and Frick, 1972) have examined the relevance of house-dust mites in childhood allergic disease and their contribution to the vast problem of the wheezing child. The aim of this paper is to present evidence of their role as an offending allergen in allergic asthma of childhood using ecological, clinical, and immunological methods.

\section{Patients and methods}

The patients consisted of 133 unselected children who were attending hospital with symptoms of recurrent wheezing and who could be deemed on clinical grounds to be suffering from asthma. The age and sex

Received 5 March 1974. distribution is shown in Fig. 1. A control group of 51 children was used. These were children in hospital for various reasons but with no clinical evidence of allergic disease. Blood samples were obtained from this group when they were bled for other reasons.

Allergen extracts were skin test solutions: $D$. pteronyssinus $1 \% \mathrm{w} / \mathrm{v}$, Dermatophagoides farinae $1 \% \mathrm{w} / \mathrm{v}$, house-dust $150 \% \mathrm{w} / \mathrm{v}$, grass pollen mix (Group B.2) $2.5 \% \mathrm{w} / \mathrm{v}$, and mould mix (Group A.13) $5 \% \mathrm{w} / \mathrm{v}$. Freeze-dried extracts of $D$. pteronyssinus and $D$. farinae and their respective culture media were also used.

Skin tests were performed on all children by the single prick method on the flexor surface of the forearm. Control children were only tested after obtaining informed parental consent. The weal diameter was

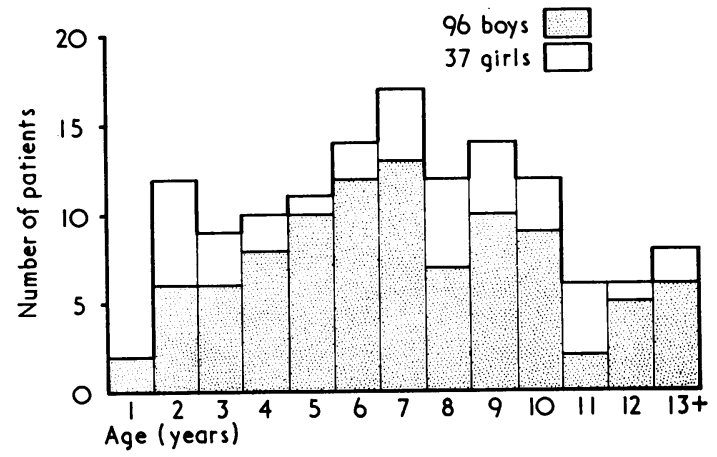

Fig. 1.-Age and sex distribution of the study group of asthmatic children. 
measured after 10 to 15 minutes and recorded. Control solutions of $0.5 \%$ phenolsaline and $1 \%$ solution of freeze-dried extract of $D$. farinae culture medium were also employed.

Nasal provocation tests were performed using solutions of freeze-dried extract of $D$. farinae in $0.5 \%$ phenolsaline. $0.05 \mathrm{ml}$ of this extract was applied to the nasal septum, using a $1 \mathrm{ml}$ plastic syringe, in tenfold increases of strength $(0.001 \%, 0.01 \%, 0.1 \%$, and $1 \%$ solutions). The test was positive if unequivocal symptoms of sneezing, rhinorrhoea, and nasal blockage occurred within 15 minutes and were accompanied by swelling of the nasal tubinates and a mucoid discharge. A control solution of $0.5 \%$ phenolsaline was always employed.

Precipitins against $D$. farinae were looked for in the sera of 36 patients by the Ouchterlony double diffusion in agar technique (Ouchterlony, 1958), using dilutions of freeze-dried extract of $D$. farinae. The dilutions employed were $10 \mathrm{mg} / \mathrm{ml}, 1 \mathrm{mg}, 0.1 \mathrm{mg}$, and $0.01 \mathrm{mg}$. Specific IgE in the sera was measured by the modified radioallergosorbent test (RAST) described by Sarsfield and Gowland (1973). Specific IgE was deemed to be present in significant amounts if the final radioactivity in the test was twice that of aliquots of pooled umbilical cord sera incorporated into each test run.

Ecological studies of the house-dust mite were performed on mattress-dust samples obtained from domestic and hospital environments, and also from mattresses in two residential schools for 'delicate' children. The dust samples were obtained by a standardized brushing procedure of the top surfaces of the mattresses onto black paper. The dust was transferred to a Petri dish, covered with $90 \%$ lactic acid, and incubated for 2 days at $50-55^{\circ} \mathrm{C}$. After this time the mites could be readily identified floating on the fluid surface and the number of $D$. pteronyssinus species in each sample counted (A. M. Cunnington, personal communication, 1971).

\section{Asthmatic children.}

Clinical history. The majority, 125/133 (94\%), experienced perennial wheezing. A history of house-dust sensitivity was obtained in $30 / 133$ (23\%), seasonal pollen sensitivity in $32 / 133(24 \%)$, and emotional factors were indicated in $58 / 133$ (44\%).

Skin tests. The incidence of positive prick test reactions (weal diameter $\geqslant 2 \mathrm{~mm}$ ) was $38 \%$ to mould mix and $59 \%$ to grass pollens. The high incidence of positive reactions to house-dust $(84 \%), D$. pteronyssinus ( $80 \%$ ), and $D$. farinae ( $79 \%$ ) confirmed the common occurrence of skin sensitivity to these allergens in asthmatic children. The mean weal diameters to $D$. pteronyssinus extract in the very young children were reasonably large, being $7 \cdot 0 \pm 1 \cdot 52,4 \cdot 7 \pm 1 \cdot 9,4 \cdot 7 \pm 1 \cdot 4,6 \cdot 0 \pm 2 \cdot 4 \mathrm{~mm}$ in the 2 nd, 3rd, 4 th, and 5 th years of life, respectively. No 'late' skin reactions were observed.

It is interesting to note that the development of skin sensitivity to the mite occurred at a much earlier age when compared with two other common inhalant allergens, grass pollens and moulds (Fig. 2).

Nasal provocation tests. 45 children had nasal provocation tests with the extract of $D$. farinae; 36 ( $80 \%)$ gave immediate positive reactions and 9 $(20 \%)$ were negative. The mean weal diameter of positive skin tests to $D$. farinae of the group with a negative nasal response was $3.7 \mathrm{~mm}$ in contrast to $5.7 \mathrm{~mm}$ where the nasal test was positive. 'Late reactions' occurring within 48 hours of the test, consisting of nasal symptoms and/or wheezing, were noted in $24(65 \%)$ out of 37 children on whom information on these possible reactions was available.

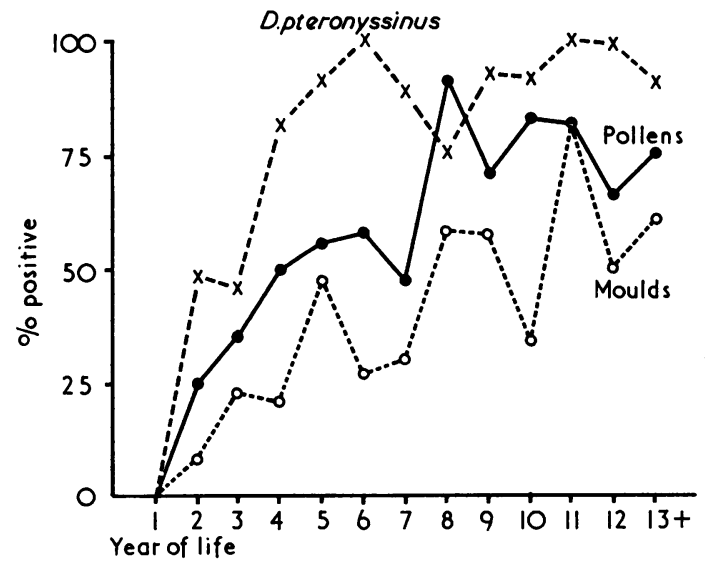

Fig. 2.-Incidence of positive skin tests to 3 common allergens in each age group of asthmatic children.

Specific IgE. Significant serum levels of specific IgE against $D$. pteronyssinus were detected in 73/133 (59\%) and against $D$. farinae in 58/133 (44\%). In no case was a negative skin test associated with the presence of specific IgE. The development of a positive skin test and the presence of specific serum IgE to $D$. pteronyssinus in this group of asthmatic children is shown in Fig. 3. A possible interpretation of the excess of positive skin reactions is that skin sensitivity may develop before specific IgE appears in the serum in significant amounts and may also persist after disappearance of this IgE from the circulation. The concurrence of specific serum IgE with a positive skin test increases with increasing weal diameter (Fig. 4).

A comparison of skin test and nasal provocation test results with the presence of specific serum IgE 


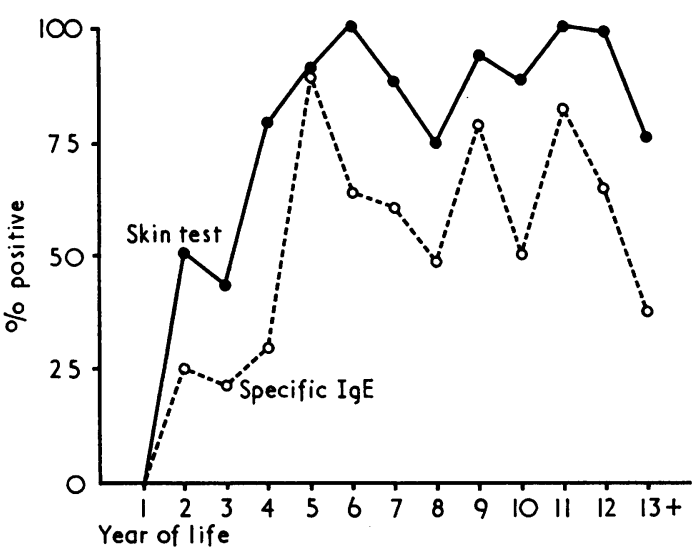

FIG. 3.-Incidence of positive skin tests and presence of specific serum $\operatorname{IgE}$ to $\mathrm{D}$. pteronyssinus in each age group.

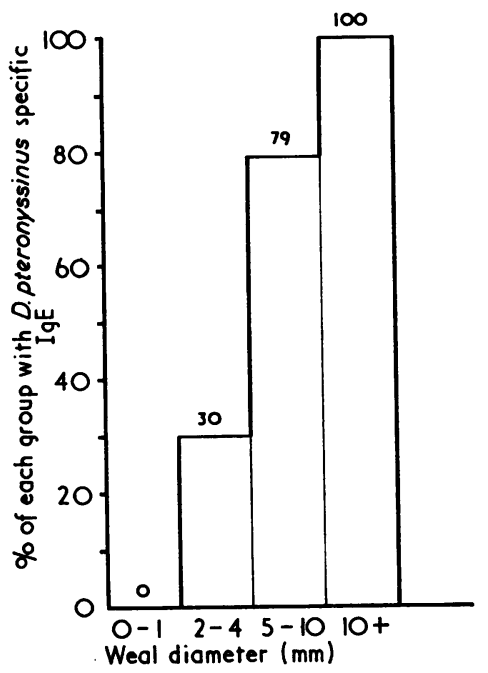

FIG. 4.-Relation of weal diameter to the presence of specific serum IgE to D. pteronyssinus.

to $D$. farinae is shown in Table I. D. farinae extract was used for nasal testing, as this was the only mite extract obtainable in sufficient quantities at the time of the investigation. There is a higher degree of concordance between nasal tests and the presence of specific IgE than between skin tests and specific IgE. Also, a negative skin test appears to be strong evidence against the clinical importance of the mite as an offending allergen.

Precipitins against D. farinae antigens. Serum samples from 36 children were examined for precipitins against various concentrations of $D$.
TABLE I

D. farinae allergen: relation of skin and nasal provocation tests to the presence of specific serum IgE

\begin{tabular}{l|c|c|c|c}
\hline \multirow{2}{*}{ Test } & $\begin{array}{c}\text { Results } \\
\text { of test }\end{array}$ & \multicolumn{2}{|c|}{ Presence of specific IgE } & $\begin{array}{c}\text { Overall } \\
\text { agreement } \\
(\%)\end{array}$ \\
\cline { 2 - 4 } & + & - & 0 \\
\hline Skin & + & 58 & 43 & 68 \\
Nasal & - & 0 & 32 & 6 \\
provocation & + & 27 & 9 & 80 \\
\hline
\end{tabular}

farinae extract. These were never detected by the method used. The case selection included serum from 22 patients with specific IgE and 20 children who had positive nasal provocation tests, 19 of whom had experienced 'late' reactions.

Control children. All 51 children in this group were skin tested to the 5 allergen extracts. Positive results were obtained to house-dust in $4 ; D$. pteronyssinus in $3 ; D$. farinae in 3 ; grass pollens in 3 ; and to mould extract in none. 10 of the 13 positive skin reactions were shown by only 3 patients. All sera were examined for specific IgE against $D$. farinae. This was detected in only 2 children; 1 of these gave a $5 \mathrm{~mm}$ weal skin reaction to this allergen and the other child had a negative skin test. A limited number (11) were examined for specific IgE against $D$. pteronyssinus; this was not detected. 74 asthmatic and 51 control children were skin tested with a $1 \%$ solution of a freeze-dried extract of medium on which $D$. farinae was cultivated. 3 asthmatic children gave positive reactions (weal diameters 2,2 , and $3 \mathrm{~mm}$ ), the rest were negative. 19 nasal provocation tests with this solution in $D$. farinae positive nasal reactors were negative. Specific IgE to this medium extract was detected in $2 / 32$ randomly selected serum samples from the asthmatics. The 3 control patients with positive skin tests were negative.

Specific IgE against $D$. pteronyssinus culture medium was not detected in the sera of 19 randomly selected children, 9 of whom had specific IgE against D. pteronyssinus allergens.

It seems, therefore, that the antigens contained in these culture media had no significant effect on the validity of the results of the tests to show sensitization to the mite allergens.

Ecological studies. These were designed to assess and compare the levels of mite infestation in environmental situations peculiar to children. Comparisons are notoriously difficult and mite 
counts expressed with reference to sample weight may be misleading due to the other heterogeneous components of house-dust. Attention was directed to various sleeping environments of children, and mite counts expressed as mites $/ \mathrm{m}^{2}$ of mattress area examined (Table II).

TABLE II

Mite infestation in relation to sleeping environments of children

\begin{tabular}{l|c|c|c}
\hline \multicolumn{1}{c|}{$\begin{array}{c}\text { Environmental source } \\
\text { of samples }\end{array}$} & $\begin{array}{c}\text { No. of } \\
\text { samples } \\
\text { collected }\end{array}$ & $\begin{array}{c}\text { No. } \\
\text { infested }\end{array}$ & $\begin{array}{c}\text { Mean mite } \\
\text { count/m } \text { of }^{2} \\
\text { all samples }\end{array}$ \\
\hline $\begin{array}{l}\text { Perambulator mattresses } \\
\text { Cot mattresses }\end{array}$ & 10 & 1 & $2 \cdot 08$ \\
$\begin{array}{l}\text { Domestic single-bed } \\
\text { mattresses }\end{array}$ & 10 & 9 & $6 \cdot 48$ \\
$\begin{array}{l}\text { Hospital ward mattresses } \\
\text { Residential school } \\
\text { dormitory mattresses }\end{array}$ & 15 & 10 & $24 \cdot 00$ \\
& 17 & 13 & 0 \\
\hline
\end{tabular}

Opportunities for exposure to the mite allergen in the sleeping environment are low in the early years but rise dramatically on transference to a bed. Many of the domestic environments studied were dry and centrally heated and these often revealed high levels of mite infestation of the beds. Dust obtained from surfaces of upholstered furniture revealed infestation with an average count of 94 mites $/ \mathrm{m}^{2}$. Other observations on levels of domestic mite infestation, while not allowing strict comparisons, suggested that floor-dust was much less heavily infested than bed-dust; infestation of soft toys (teddy bears, golliwogs, etc.) was detected regularly and the importance of these articles as vectors of the mite allergen is obvious.

Mites were absent from hospital beds, and only very low levels of infestation could be detected in residential schools for 'delicate' children to which asthmatic children are sometimes referred.

\section{Discussion}

The 133 asthmatic children in the present study were unselected apart from being referred to hospital for advice or treatment. This contrasts with other study groups where only known house-dust sensitive patients were examined (Brown and Filer, 1968; Maunsell et al., 1968; Bullock and Frick, 1972). The patients in the series reported by Smith et al. (1969) were unselected asthma clinic patients but were all of school age and were investigated only by skin testing.

Opportunities for exposure to the house-dust mite allergen probably exist in every household in the
United Kingdom regardless of the presence or absence of an efficient heating system. This observation was previously made by Maunsell $e t$ al. (1968) who suggested that the 'microclimate' of the mattress was as important as the conditions of the house itself. Climatic factors have probably been overstressed in the past. The house-dust mite can withstand periods of comparative drought and it flourishes in relatively undisturbed situations such as the beds in spare bedrooms and holiday cottages (Hughes and Maunsell, 1973). The high degree of infestation of upholstered furniture probably reflects the requirement of $D$. pteronyssinus for human skin scales as its major source of food. This source is low in sleeping situations where plastic covered mattresses are used (perambulators, cots, hospital beds) and where better hygiene measures remove both the mites and their food. Highest exposure would occur in children when they are transferred to an ordinary bed in the latter half of the preschool years. This correlated with the rapid rise in the frequency of mite hypersensitivity during this age period, as shown by the appearance of positive skin tests and specific IgE in the serum in this study (Fig. 3).

The low or zero levels of mite infestation in beds of hospitals or residential schools could account for the frequently observed spontaneous improvement in symptoms after admission to these institutions. Hence, the avoidance of this potent allergen may well replace the old concept of 'parentectomy' as the mechanism for this improvement.

Only $23 \%$ of the present series gave a positive history of house-dust sensitivity. Nocturnal symptoms are common in mite-sensitive children (Smith, 1970), but the history is only of limited usefulness in the problem of perennial wheezing. Skin testing remains the mainstay of offending allergen identification. With mite allergy it was evident that the greater the size of the skin reaction the more likely was specific serum IgE to be present and hence presumed to be associated with clinical hypersensitivity. However, 'false positive' skin test results with absence of circulating specific IgE occurred commonly. A negative skin test probably excludes mite allergy.

Nasal provocation tests are time consuming, sometimes difficult to interpret, and impossible to perform in the very young child. However, they probably reflect bronchial sensitivity more accurately than skin tests and it was found that their results correlated much better with the presence or absence of specific IgE.

The future possibility of extended use of 'in vitro' techniques for detecting specific IgE as an aid to 
allergen identification has recently been stressed by Sarsfield and Gowland (1973) and a modified method described. The present study using this method (employing commercially available materials) confirmed its specificity with regard to the mite allergen without interference from the constituents of the mite culture medium.

The contribution of Type III immune-reactions in mite asthma remains controversial. There were no late skin reactions and no precipitins found in any sera tested. Similar results were reported by McAllen et al. (1970), but Romagnani et al. (1973) recently reported the presence of precipitins to mite in both mite-sensitive patients and normals, employing more sensitive techniques. The detection of such antibodies may be of importance in the selection of patients likely to benefit from specific hyposensitization procedures (D'Souza et al., 1973).

I am grateful to Professor G. Gowland for provision of laboratory facilities and his help and supervision of this study; and I thank Professor R. W. Smithells and the paediatricians of the Leeds hospitals for referring patients and for their enthusiastic support and interest. Bencard Ltd. supplied the allergen extracts.

\section{REFERENCES}

Brown, H. M., and Filer, J. L. (1968). Rôle of mites in allergy to house-dust. British Medical fournal, 3, 646.

Bullock, J. D., and Frick, O. L. (1972). Mite sensitivity in house dust-allergic children. American fournal of Diseases of Children, $123,222$.

Cooke, R. A. (1922). Studies in specific hypersensitiveness. fournal of Immunology, 7, 147.

Dekker, H. (1928). Asthma und Milben. Münchener Medizinische Wochenschrift, 75, 515.

D'Souza, M. F., Pepys, J., Wells, I. D., Tai, E., Palmer, F., Overell, B. G., McGrath, I. T., and Megson, M. (1973). Hypo- sensitization with Dermatophagoides pteronyssinus in house dust allergy: a controlled study of clinical and immunological effects. Clinical Allergy, 3, 177.

Frankland, A. W. (1971). Asthma and mites. Postgraduate Medical fournal, $47,178$.

Hughes, A. M., and Maunsell, K. (1973). A study of a population of house dust mite in its natural environment. Clinical Allergy, 3, 127.

Kern, A. (1921). Dust sensitisation in bronchial asthma. Medical Clinics of North America, 5, 751.

McAllen, M. K., Assem, E. S. K., and Maunsell, K. (1970). Housedust mite asthma: results of challenge tests on five criteria with Dermatophagoides pteronyssinus. British Medical fournal, 2, 501.

Maunsell, K., Wraith, D. G., and Cunnington, A. M. (1968). Mites and house-dust allergy in bronchial asthma. Lancet, 1, 1267.

Ouchterlony, O. (1958). Diffusion-in-gel methods for immunological analysis. In Progress in Allergy, Vol. 5, p. 1. Ed. by P. Kallos. Karger, Basle and New York.

Romagnani, S., Biliotti, G., Passaleva, A., and Ricci, M. (1973). Mites and house dust allergy. III. In vitro lymphocyte transformation and precipitating antibody to house dust and mite (Dermatophagoides pteronyssinus) extract in atopic and non-atopic individuals. Clinical Allergy, 3,51.

Sarsfield, J. K., and Gowland, G. (1973). A modified radioallergosorbent test for the in vitro detection of allergen antibodies. Clinical and Experimental Immunology, 13, 619.

Smith, J. M. (1970). Clinical findings in children with allergy to the house-dust mites. Acta Allergologica, 25, 37.

Smith, J. M., Disney, M. E., Williams, J. D., and Goels, Z. A. (1969). Clinical significance of skin reactions to mite extracts in children with asthma. British Medical fournal, 2, 723.

Voorhorst, R., Spieksma-Boezman, M. I. A., and Spieksma, F. Th. M. (1964). Is a mite (Dermatophagoides sp.) the producer of the house-dust allergen? Allergie und Asthma, 10, 329.

Voorhorst, R., Spieksma, F. Th. M., Varekamp, H., Leupen, M. J., and Lyklema, A. W. (1967). The house-dust mite (Dermatophagoides pteronyssinus) and the allergens it produces. Identity with the house-dust allergen. Fournal of Allergy, 39, 325.

Correspondence to Dr. J. K. Sarsfield, Department of Paediatrics and Child Health, University of Leeds, 27 Blundell Street, Leeds LS1 3ET. 